\title{
(6) OPEN ACCESS \\ Association of genital human papillomavirus infection with HIV acquisition: a systematic review and meta-analysis
}

\author{
Pascale Lissouba, ${ }^{1}$ Philippe Van de Perre, ${ }^{2,3,4}$ Bertran Auvert ${ }^{1,5,6,7}$
}

- Additional material is published online only. To view please visit the journal online (http://dx.doi.org/10.1136/ sextrans-2011-050346).

${ }^{1}$ CESP INSERM-UVSQ UMRS1018, Villejuif, France ${ }^{2}$ INSERM U1058, Montpellier, France

${ }^{3}$ UFR of Medicine, University Montpellier 1, Montpellier, France

${ }^{4}$ Department of BacteriologyVirology, CHU Montpellier,

Montpellier, France ${ }^{5}$ University of Versailles-SaintQuentin, Versailles, France ${ }^{6}$ Assistance Publique- Hôpitaux de Paris, Hôpital AmbroiseParé, Boulogne, France ${ }^{7}$ Institut Universitaire de France, France

\section{Correspondence to} Professor Bertran Auvert, CESP INSERM-UVSQ UMRS-1018, Hôpital Paul Brousse, 16 avenue Paul Vaillant-Couturier, Villejuif 94807, France:

bertran.auvert@uvsq.fr

Received 3 November 2011 Revised 30 April 2013 Accepted 7 May 2013 Published Online First 12 June 2013

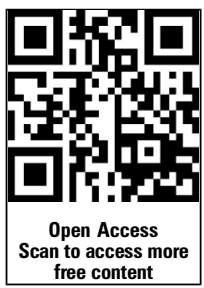

\section{SLinked}

- http://dx.doi.org/10.1136/ sextrans-2012-050870

To cite: Lissouba $P$, Van de Perre P, Auvert B. Sex Transm Infect 2013:89: 350-356.

\section{ABSTRACT \\ Objectives To conduct a systematic review and a} meta-analysis of epidemiological studies investigating the association of genital human papillomavirus (HPV) infection and HIV acquisition.

Design Systematic review and meta-analysis.

Data Sources Scientific databases and conference abstracts were systematically searched to identify all relevant studies published up to 31 January 2012. Search terms included 'HIV', 'HPV', 'human papillomavirus' and 'papillomaviridae' as keywords or text, in the title or abstract.

Methods To be eligible for inclusion, a study had to be conducted among humans, report data on HIV incidence, and assess genital HPV infection. Summary ORs and $95 \% \mathrm{Cl}$ s were estimated from the extracted data using random-effect meta-analysis. Subgroup analyses were conducted for high-risk (HR) and low-risk (LR) HPV oncogenic risk groups. Between-study heterogeneity and publication bias were assessed. Results of 2601 identified abstracts, six observational studies, comprising 6567 participants were retained for the systematic review and the meta-analysis. HIV acquisition was significantly associated with HPV infection (summary OR=1.96; 95\% Cl 1.55 to 2.49). HIV incident infection was significantly associated with HR-HPV in five of six studies and with LR-HPV in two out of five. The association was significant for HR-HPV (summary $\mathrm{OR}=1.92 ; 95 \% \mathrm{Cl} 1.49$ to 2.46 ) and borderline for LR-HPV. No between-study heterogeneity was detected. There was a borderline indication of publication bias.

Conclusions Further research is needed to elucidate the biological mechanisms involved, and assess the effect of HPV vaccination on HIV acquisition, using vaccines with broad coverage of HPV genotypes. Such research could have important public health implications for HIV prevention.

\section{INTRODUCTION}

Evidence from systematic reviews and meta-analyses of epidemiological studies suggests that sexually transmitted infections (STI) such as Neisseria gonorrhoea, Chlamydia trachomatis, Trichomonas vaginalis, infectious syphilis and herpes simplex virus-2 (HSV-2) play a role in HIV acquisition. ${ }^{1-4}$ A modelling study has estimated that over $50 \%$ of HIV sexual transmission could be attributed to STI. ${ }^{5}$ The contribution of STI to the HIV epidemic is still being debated, due to the observational nature of the evidence, ${ }^{6}$ and the poor efficacy of randomised clinical trials of STI management on HIV acquisition. ${ }^{7}$ Nonetheless, there is biological plausibility to the causal association of STI with HIV acquisition, which is corroborated by the enhanced susceptibility of STI-affected individuals to HIV. ${ }^{8}$

Little research had been conducted on the association of HIV acquisition with genital human papillomavirus (HPV) infection, the most common STI worldwide, ${ }^{10}$ and a major cause of morbidity and mortality, contributing to up to $5.2 \%$ of the cancer burden in the world. ${ }^{11}$ Genital HPV, which targets the basal epithelial cells of the mucosal surface, ${ }^{12}$ is highly infectious, with transmissibility estimated to be higher than any other viral STI. ${ }^{12}$ Mucosal HPV genotypes are divided into high-risk (HR) and low-risk (LR) HPV based on their association with cervical malignancy. ${ }^{13}$ HR-HPV genotypes cause cervical carcinoma, one of the leading causes of cancer deaths in the world, and have been implicated in vulvar, vaginal, penile and anal cancers. ${ }^{12} 13$ LR-HPV genotypes are associated with genital warts, which negatively impact quality of life and psychosocial functioning. ${ }^{14} 15 \mathrm{HPV}$ prevalence is estimated to range from $1.6 \%$ to $41.9 \%$ among women, ${ }^{16}$ and $1.0 \%$ to $95.0 \%$ among men, ${ }^{17}$ according to factors such as setting, age and sexual behaviour.

To date, the bulk of research has investigated the link between HPV infection and HIV-serostatus. Studies indicate that HIV seropositivity is strongly associated with higher HPV prevalence, ${ }^{18-24}$ higher HPV incidence, ${ }^{21}$ a reduced likelihood of HPV infection clearance which increases the risk of related lesions, ${ }^{21} 2425$ and higher prevalence of infection with multiple HPV genotypes. ${ }^{20} 22 \quad 24$ HIV seropositivity has also been linked to highgrade and low-grade cervical squamous intraepithelial lesions, ${ }^{20} 23$ as well as invasive cervical carcinoma, a recognised AIDS-defining condition ${ }^{26}$ and a common cancer among HIV-positive women in sub-Saharan Africa. ${ }^{27}$

Research on the role of genital HPV in HIV incident infection is currently limited, whereas it is biologically plausible. HPV could predispose to HIV infection and dissemination through its disruption of the epithelium integrity and the mucosal immune system, ${ }^{27}$ by (A) altering the density and functional activities of epithelial Langerhans cells which capture infecting pathogens, ${ }^{8} 28$ (B) enabling the recruitment and activation of HIV target cells such as T-lymphocytes, ${ }^{29}$ (C) reducing the expression of proteins acting in cell adhesion and tumour suppression, $^{30}$ (D) downregulating proteins that promote the infiltration of Langerhans cells through the epithelium, ${ }^{31}$ (E) reducing the 
production of proteins involved in antimicrobial activities ${ }^{28}$ and (F) upregulating inflammatory cytokines, ${ }^{28}{ }^{29}$ which may increase HIV replication.

There have been several calls for the investigation of the association of genital HPV infection with HIV acquisition, dating as far back as $1993 .^{712} 283233$ In view of the scope and severity of both infections and their synergy, a review of the existing epidemiological evidence is warranted. Since there are now two highly efficacious vaccines against some HPV genotypes, ${ }^{34} 35$ this research may have important implications for policies on HPV vaccination and public health efforts to limit the spread of HIV.

\section{OBJECTIVES}

The objectives of this study were to systematically review, summarise, and conduct a meta-analysis of epidemiological studies investigating the association of genital HPV infection with HIV incident infection.

\section{METHODS}

The review and meta-analyses were performed according to the PRISMA 2009 (Preferred Reporting Items for Systematic Reviews and Meta-Analyses) and STROBE (Strengthening the Reporting of Observational Studies in Epidemiology) guidelines. $^{36} 37$

\section{Search strategy and selection criteria}

A bibliographic search was performed in MEDLINE, EMBASE, Web of Science and the Cochrane database, to identify all relevant epidemiologic studies published up to 31 January 2012. Search terms consisted of ('HIV' OR 'human immunodeficiency virus') AND 'HPV' OR 'human papillomavirus' OR 'papillomaviridae') as keywords or text, in the title or abstract. There were no language restrictions. This broad search strategy ensured that all preidentified eligible studies were included in the results. Abstracts from relevant conferences were also searched.

All retrieved abstracts were read by two of the review authors (PL and BA), and evaluated for eligibility. To coincide with the study objectives and be selected, a study had to be conducted among humans, report data on HIV incidence, and assess its association with genital HPV infection. Genital HPV could be reported either by oncogenic risk group (LR-HPV vs HR-HPV), individual genotypes, or as a categorical (prevalent HPV infection), or discrete (number of HPV genotypes) variable. To assess HPV as a potential risk factor of HIV acquisition, only studies assessing HPV infection before measuring HIV incidence were retained. Cohorts could include HIV seropositive individuals at baseline. Reviews, cross-sectional studies, case studies and case series were excluded.

\section{Data extraction}

The full text of the retained articles was independently read by all review authors. Data were extracted using a standardised form. Information obtained included HPV prevalence in the sample, number of HIV incident infections, unadjusted and adjusted estimates, including 95\% CIs, of the association between HPV infection and HIV acquisition, type of estimate, study setting, sample size, demographic characteristics, HPV sampling methods, length of follow-up and covariates used for adjustment in the multivariate models.

\section{Statistical analyses}

The summary ORs and 95\% CI were estimated using random-effect meta-analytic techniques because there was substantial heterogeneity between studies in terms of sample size, participants characteristics, reported HIV incidence, length of follow-up, covariates used for adjustment and HPV assessment (including sampling method, oncogenic risk group classification and measured prevalence).

The main analyses were conducted for HPV infection, regardless of oncogenic risk group. Adjusted estimates were used whenever possible. Sub-group analyses were conducted by HPV oncogenic risk group. One study ${ }^{38}$ reported estimates for three different timings of HPV assessment: at baseline, concurrently with HIV testing and within 6 months of HIV testing. This latter assessment, labelled 'recent' HPV, was used in the main analysis. Sensitivity analyses were conducted with the other two timings of assessment.

For each summary analysis, between-study heterogeneity was assessed using the I-squared statistic, ${ }^{39}$ which quantifies the degree of heterogeneity. Publication bias was evaluated using the Begg-adjusted rank correlation test, which assesses the association between the treatment effect and its variance, ${ }^{40}$ and the Egger regression asymmetry test. ${ }^{41}$ All statistical analyses were performed using the Stata Statistical Software: Release V.10 (StataCorp 2007, College Station, Texas, USA: StataCorp LP).

\section{RESULTS}

\section{Study selection}

The database search identified a total of 2601 abstracts $(2170$ articles and 431 conference proceedings). The study selection process is detailed in figure 1. After the exclusion of duplicate citations and non-relevant abstracts, 14 published studies were retained. Eight studies were rejected because they did not fulfil the inclusion criteria. Five nested cohort studies, and one casecontrol study on the association between genital HPV infection and HIV acquisition were identified. ${ }^{38}{ }^{42-46}$ Selected studies are summarised in table 1.

\section{Study characteristics}

Four studies were conducted among women ${ }^{38} 434446$ and two among men. ${ }^{42} 45$ They included a total of 6567 participants. All but one study among adult men who have sex with men $^{42}$ were conducted in sub-Saharan Africa among heterosexual adults. Two of the African studies were conducted among high-risk women who were mostly sex workers. ${ }^{43} 46$

HPV prevalence across studies reporting baseline overall HPV infection ranged from $24.5 \%$ to $56.8 \%$. In studies conducted among women, HPV testing was performed on cervical samples. HPV sampling among men included the collection of anal samples in the Chin-Hong and colleagues study ${ }^{42}$ and exfoliated cells from the glans or coronal sulcus and the penile shaft in the Smith and colleagues study. ${ }^{45}$ HPV sampling was performed by health professionals, apart from the SmithMcCune and colleagues study ${ }^{38}$ which included self-collected and clinician-collected cervical swabs.

In all six studies, HPV testing was conducted using PCR and positive HPV results were genotyped using type-specific probes on PCR products. However, these methods differed in terms of HPV genotypes detected and their classification by oncogenic risk group, with some genotypes classified as high-risk in some studies and as low-risk in others (see online supplementary appendix table S2a and S2b). Six studies reported estimates for HR-HPV and five for LR-HPV. In the subgroup analyses, the distinction between HR-HPV and LR-HPV was made according to the criteria reported in each study because genotype-specific data were not available.

Time between HPV status and HIV seroconversion assessments varied between studies. When HPV was assessed at the 
Figure 1 Flow diagram of study selection for the review and meta-analysis. Of the 2601 abstracts retrieved, 14 were selected for full reading. Based on the selection criteria, six studies were retained for the systematic review and the meta-analyses.

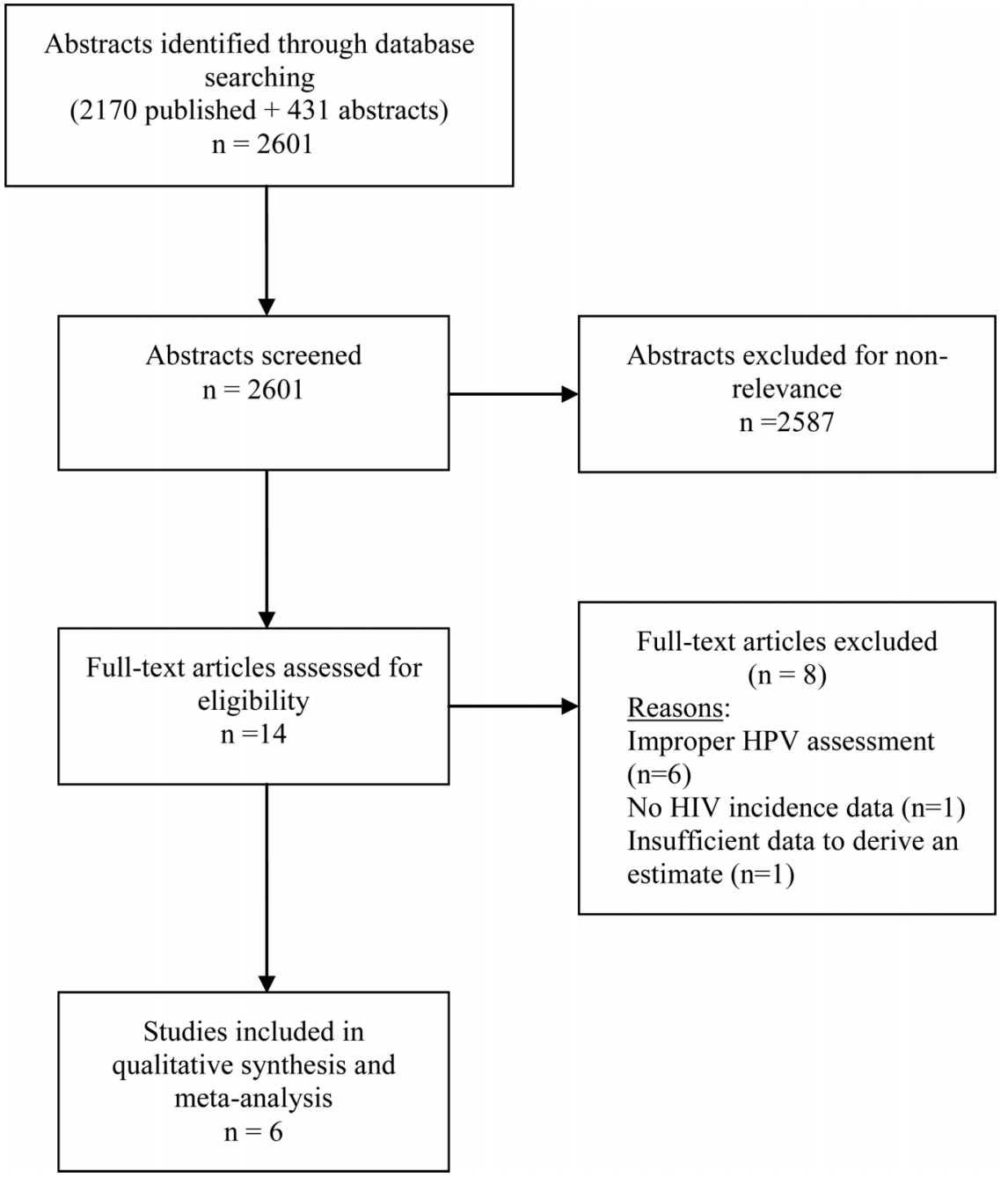

start of the follow-up period over which HIV incidence was measured (or at month 6 for one study ${ }^{43}$ ), follow-up varied between 21 and 42 months. ${ }^{38} 42434546$ The Smith-McCune and colleagues study ${ }^{38}$ also assessed incident HIV infection detected concurrently and within 6 months of HPV infection assessment. The Averbach and colleagues study ${ }^{44}$ used HPV data detected on average 80 days before HIV seroconversion.

HPV genotypes found to be associated with HIV acquisition included HPV 52, ${ }^{43}$ as well as HPV 31,58 and $70 .^{38}$ In terms of the four HPV genotypes covered by the currently available vaccines, only one study investigating individual HPV genotypes found significant positive associations between HIV acquisition and genotypes 16 and $18 . .^{45}$ None of the studies found associations with genotypes 6 and 11 .

The Auvert and colleagues study, ${ }^{46}$ the Averbach and colleagues study, ${ }^{44}$ and the Chin-Hong and colleagues study, ${ }^{42}$ found that the risk of HIV acquisition increased with the number of detected HPV genotypes. By contrast, in the Smith and colleagues study, ${ }^{45}$ risk of incident HIV infection did not differ between individuals with multiple infections versus those infected with only one genotype.

Both the Smith-McCune and colleagues study ${ }^{38}$ and the Averbach and colleagues studies ${ }^{44}$ investigated HPV persistence and clearance, and found a significant association between nonpersistent HPV and HIV acquisition. However, the definition of non-persistence differed between the studies.

\section{Study quality} able, and their 95\% CI are reported in table 1. All but one study ${ }^{43}$ reported adjusted OR. Statistically significant estimates are reported in bold. Variables included in the multivariate models are listed in online supplementary appendix table S3. Most studies controlled for age $38 \quad 42 \quad 44-46$ and HSV-2 status. $^{38} \quad 4244 \quad 45$ All studies conducted among women, and reporting adjusted estimates, controlled for condom use and sexual behaviour. ${ }^{38} 4446$ Two studies conducted in sub-Saharan ciated with HIV incidence. Measures of sexual partners' characteristics and participants' sexual behaviour were population-specific, assessed at different times during follow-up, and varied substantially across studies.

\section{Main meta-analysis}

Six studies were included in the meta-analysis. ${ }^{38} \quad 42-46$ All reported significant estimates of the association of HPV with HIV incidence. ${ }^{38} 42-46$ As shown in figure 2, the computed summary OR indicated that overall, individuals with genital HPV infection, regardless of oncogenic risk group, had twice the risk of acquiring HIV (summary OR, 1.96; 95\% CI, 1.55 to 2.49). There was no evidence of between-study heterogeneity $(p=0.484)$, suggesting that a pooled analysis was suitable.
For all six studies, unadjusted and adjusted estimates, as applicAfrica $^{3845}$ controlled for circumcision status, known to be asso- 
Table 1 Characteristics of identified studies investigating the association between genital HPV infection and HIV acquisition

\begin{tabular}{|c|c|c|c|c|c|c|c|c|c|c|c|}
\hline \multirow{2}{*}{$\begin{array}{l}\text { Study type; } \\
\text { first author; year; }\end{array}$} & \multirow{2}{*}{$\begin{array}{l}\text { Study } \\
\text { setting } \\
\text { lies }\end{array}$} & \multicolumn{3}{|l|}{ Study population } & \multirow[t]{2}{*}{ HPV sampling } & \multirow[t]{2}{*}{$\begin{array}{l}\text { Length of } \\
\text { follow-up } \\
\text { (months) }\end{array}$} & \multirow[t]{2}{*}{$\begin{array}{l}\text { Number of } \\
\text { incident HIV } \\
\text { cases }\end{array}$} & \multirow[t]{2}{*}{$\begin{array}{l}\text { Type of } \\
\text { ratio } \\
\text { estimate }\end{array}$} & \multirow[t]{2}{*}{$\begin{array}{l}\text { HPV } \\
\text { prevalence }\end{array}$} & \multirow[t]{2}{*}{$\begin{array}{l}\text { HIV incidence ratio } \\
\text { estimates (crude) } \\
(95 \% \mathrm{Cl})\end{array}$} & \multirow[t]{2}{*}{$\begin{array}{l}\text { HIV incidence ratio } \\
\text { estimates (adjusted) } \\
(95 \% \mathrm{Cl})\end{array}$} \\
\hline & & $\begin{array}{l}\text { Gender and } \\
\text { population type }\end{array}$ & $\begin{array}{l}\text { Age } \\
\text { (years) }\end{array}$ & $\mathrm{n}$ & & & & & & & \\
\hline $\begin{array}{l}\text { Chin-Hong et al } \\
2009\end{array}$ & USA & $\begin{array}{l}\text { Men } \\
\text { Men who have } \\
\text { sex with men }\end{array}$ & $\begin{array}{l}16 \text { and } \\
\text { older }\end{array}$ & 1409 & Anal swabs at baseline & 48 & 51 & HR & $\begin{array}{l}\text { HPV: } 56.8 \% \\
\text { HR-HPV: } 26.4 \% \\
\text { LR-HPV: } 25.6 \%\end{array}$ & $\begin{array}{l}3.6(1.5 \text { to } 8.4)^{*} \\
\text { NR } \\
\text { NR }\end{array}$ & $\begin{array}{l}3.5(1.2 \text { to } 10.6)^{*} \\
N R \\
N R\end{array}$ \\
\hline $\begin{array}{l}\text { Smith-McCune } \\
\text { et al } 2010\end{array}$ & Zimbabwe & $\begin{array}{l}\text { Women general } \\
\text { population }\end{array}$ & $18-49$ & 1987 & $\begin{array}{l}\text { Cervical swabs at baseline and } \\
12 \text {-month visit; quarterly vaginal } \\
\text { swabs }\end{array}$ & 21 & 88 & HR & $\begin{array}{l}\text { Baseline HPV: } \\
24.5 \% \\
\text { Baseline } \\
\text { HR-HPV: } 16.1 \% \\
\text { Baseline } \\
\text { LR-HPV: } 10.8 \%\end{array}$ & $\begin{array}{l}\mathrm{NR} \\
\mathrm{NR} \\
\mathrm{NR}\end{array}$ & $\begin{array}{l}1.6 \text { (1.0 to } 2.7) \\
2.0(1.2 \text { to } 3.2) \\
1.5 \text { (0.92 to } 2.4)\end{array}$ \\
\hline Smith et al 2010 & Kenya & $\begin{array}{l}\text { Men general } \\
\text { population }\end{array}$ & $18-24$ & 2168 & $\begin{array}{l}\text { Exfoliated penile cells from glans/ } \\
\text { coronal sulcust at baseline }\end{array}$ & 42 & 63 & HR & $\begin{array}{l}\text { HPV: } 50.2 \% \\
\text { At least one } \\
\text { HR-HPV¥: } \\
34.8 \% \\
\text { Only LR-HPV¥: } \\
15.5 \%\end{array}$ & $\begin{array}{l}\mathrm{NR} \\
\mathrm{NR}\end{array}$ & $\begin{array}{l}1.8(1.1 \text { to } 2.9) \\
1.5(0.9 \text { to } 2.6)\end{array}$ \\
\hline $\begin{array}{l}\text { Veldhuijzen et al } \\
2010\end{array}$ & Rwanda & $\begin{array}{l}\text { Women high risk } \\
\text { (96\% sex workers) }\end{array}$ & $\begin{array}{l}\text { median } \\
25\end{array}$ & 324 & Cervical samples at month 6 & 24 & 10 & OR & $\begin{array}{l}\text { HPV: } 47.8 \% \\
\text { HR-HPV: } 33.3 \% \\
\text { LR-HPV: } 34.3 \%\end{array}$ & $\begin{array}{l}\mathrm{NR} \\
4.9(1.2 \text { to } 19.7) \\
\mathrm{NR}\end{array}$ & $\begin{array}{l}\text { NR } \\
\text { NR } \\
\text { NR }\end{array}$ \\
\hline Auvert et al 2011 & $\begin{array}{l}\text { South } \\
\text { Africa }\end{array}$ & $\begin{array}{l}\text { Women } \\
\text { High-risk (all sex } \\
\text { workers) }\end{array}$ & $\begin{array}{l}\text { median } \\
24\end{array}$ & 88 & $\begin{array}{l}\text { first available cervico-vaginal } \\
\text { rinses of } 3 \text { obtained during } \\
\text { follow-up, before seroconversion }\end{array}$ & 30 (median) & 25 & $H R$ & $\begin{array}{l}\text { HPV: } \\
\text { HR-HPV: } 70.5 \% \\
\text { LR-HPV: } 60.2 \%\end{array}$ & $\begin{array}{l}\text { NR } \\
1.5(1.1 \text { to } 2.1) \S \\
1.1(0.77 \text { to } 1.5) \S\end{array}$ & $\begin{array}{l}\text { NR } \\
1.7(1.0 \text { to } 2.7) \S \\
0.95(0.68 \text { to } 1.3) \S\end{array}$ \\
\hline \multicolumn{12}{|l|}{ Case-control Study } \\
\hline $\begin{array}{l}\text { Averbach et al } \\
2010\end{array}$ & Zimbabwe & $\begin{array}{l}\text { Women general } \\
\text { population }\end{array}$ & $18-35$ & $\begin{array}{l}145 \text { cases } \\
\text { and } 446 \\
\text { controls }\end{array}$ & $\begin{array}{l}\text { Cervical swabs at } t_{-1} \text { ( } t_{0}=\text { time of } \\
\text { HIV detection) }\end{array}$ & $\begin{array}{l}\mathrm{t}_{0}-\mathrm{t}_{-1}=80.5 \text { days } \\
21.9\end{array}$ & 145 & OR & $\begin{array}{l}\text { HPV : } 49.1 \% \\
\text { Any HR-HPV: } \\
37.1 \% \\
\text { Only LR-HPV: } \\
12.0 \%\end{array}$ & $\begin{array}{l}2.7(1.7 \text { to } 4.1) \\
2.7(1.7 \text { to } 4.3) \\
2.5(1.3 \text { to } 4.6)\end{array}$ & $\begin{array}{l}2.4(1.5 \text { to } 4.0) \\
2.3(1.4 \text { to } 3.9) \\
2.8(1.3 \text { to } 5.9)\end{array}$ \\
\hline
\end{tabular}

Bold indicates statistically significant estimates.

*Infection with two or more HPV genotypes.

FHPV infections with multiple HPV types were considered high risk if one or more HR-HPV type was detected. All the others were considered LR-HPV infections.

ҒHPV infections with multiple HPV types were consider
§lnfection with one HPV genotype versus no HPV.

HPV, human papillomavirus; HR-HPV, high-risk HPV; IRR, incidence rate ratio; LR-HPV, low-risk HPV; NR, not reported; RCT, randomised control trial. 
Figure 2 Combined estimate of the association of human papillomavirus infection with HIV acquisition. The weights and combined estimate were computed using random-effect meta-analysis. Estimates from individual studies and the combined estimate represented on the $x$-axis are in the natural log scale.

Study

ID

ES $(95 \% \mathrm{CI})$

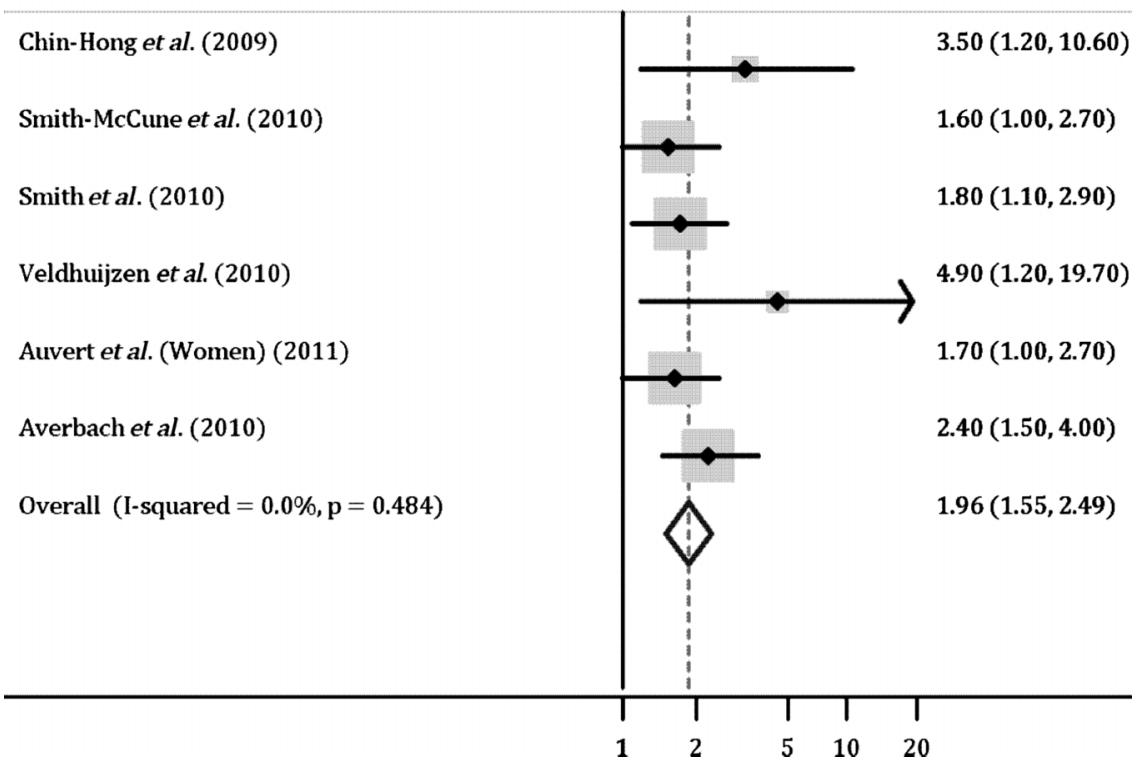

This study is based on evidence from observational research,

\section{Sub-group analyses}

When the association with HIV acquisition was investigated by subgroups, it was found to be statistically significant with HR-HPV (summary OR, 1.92; 95\% CI, 1.49 to 2.46; test of heterogeneity $\mathrm{p}=0.511$ ), and borderline with LR-HPV (summary OR, 1.53 ; 95\% CI, 0.96 to 2.42 ; test of heterogeneity $\mathrm{p}=0.029)$.

\section{Sensitivity analyses}

The summary ORs computed with the alternative assessments ${ }^{38}$ for both main and subgroup analyses were almost identical to the original estimates (see online supplementary appendix).

\section{Publication bias}

The funnel plot for the detection of publication bias associated with the random-effect meta-analysis of HPV and HIV acquisition is presented in figure 3. It appears that studies with larger SEs tended to report larger estimates. However, the Begg's test was not statistically significant $(p=0.339)$. Visually, the funnel plots seemed asymmetrical, indicating a possible publication bias towards studies reporting significant associations. This was confirmed statistically by the Egger's test, which indicated a borderline statistically significant publication bias $(p=0.054)$.

In the subgroup analyses, no significant publication bias was detected for HR-HPV (Begg's test $p=0.806$; Egger's test $\mathrm{p}=0.181$ ). There was a significant publication bias for LR-HPV (Begg's test $p=0.089$; Egger's test $p=0.022$ ).

\section{DISCUSSION}

This systematic review and meta-analysis investigates both qualitatively and quantitatively empirical evidence of the association between genital HPV infection and HIV acquisition. The fact that all studies included have been published recently indicates that this is a topic which has been overlooked in past HIV prevention research. Our findings show that genital HPV infection is associated with incident HIV infection, and that this association is significant with HR-HPV, and borderline with LR-HPV. hence it cannot distinguish between causality and confounding.

\section{Biological mechanisms}

The enabling effect of HPV on HIV acquisition is plausible, primarily because HPV is assumed to be more infectious than $\mathrm{HIV}^{12}$ and HPV prevalence exceeds that of HIV, even in areas where HIV is endemic. Several hypotheses may explain a possible higher susceptibility of HPV-infected individuals to HIV, including HPV-induced epithelial breaches or displasia, T-lymphocytes influx, the production of proinflammatory cytokines, or a reduced secretion of proteins involved in the

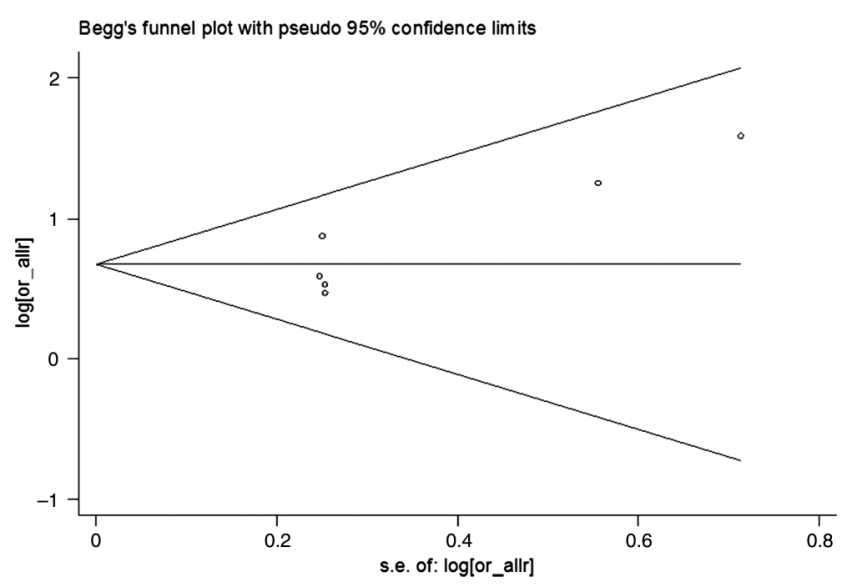

Figure 3 Funnel plot for the meta-analysis of human papillomavirus (HPV) and HIV acquisition The horizontal line represents the natural $\log (\ln )$ of the combined OR. The funnel lines represent the $95 \%$ pseudo confidence limits for this estimate. The graph suggests that estimates of the association between HPV and HIV acquisition reported by studies with larger SEs tend to be larger. Furthermore, the graph is slightly asymmetrical, indicating a possible publication bias towards studies reporting significant associations. 
immunologic response, which may all promote HIV entry and replication. ${ }^{8}$

However, the observed association could be due to host susceptibility for HPV and $\mathrm{HIV}^{47}$ The two viruses share common mechanical access to susceptible cells and common portals of entry, such as the squamo-columnar junctions in the anogenital mucosae, which are prime sites of metaplastic conversion, and prone to viral establishment. ${ }^{28}$ Adhesion molecules are less densely expressed at these sites, favouring paracellular permeation. ${ }^{28}$

Breaches of the mucosal surface, which enable HPV to access lower layers of stratified epithelia during its initial invasion phase, may favour HIV acquisition as well. ${ }^{28}$

Lastly, the association could be mediated by other STI. For instance, HPV is more frequent in HSV-2 infected individuals. HSV-2 replication, associated with primary infection and in-situ reactivation of latent infections, facilitates HIV acquisition. ${ }^{48}$ Thus, remote confounding could partly explain the association observed.

\section{Study limitations}

There are several limitations to this meta-analysis. First, it was conducted among a small number of studies, so it is underpowered, which may have affected the I-squared statistic. ${ }^{39}$ Second, all studies were observational, which increases the likelihood of bias. Third, the qualitative review of the studies indicated substantial variations in terms of study design, participant characteristics, HPV status assessment, and covariates used in the adjusted models. Two salient variations were: (A) HPV sampling among men, which was not standardised, and could explain the differences in HPV and HR-HPV prevalences observed ${ }^{49}$ and (B) the classification of HPV genotypes by oncogenic risk group, which differed across studies. Since the genotype-specific prevalences were not consistently reported, it was not possible to evaluate how these differential classifications may have affected the subgroup estimates. Similarly, it was not possible to explore genotype-specific associations of HPV with HIV as data was not available. Another important issue was the time between HPV status assessment and HIV testing, which varied across studies. It cannot be excluded that the association is time-dependent, and that the transient nature of HPV infection ${ }^{50}$ could have affected its strength. Fourth, metaregressions to examine the impact of factors, such as study site, sexual risk behaviour, as well as relevant analyses stratified by sampling sites and methods, could not be performed for lack of power. Fifth, the adjustments for the multivariate estimates used in the meta-analyses were performed on different variables. Sixth, publication bias was suggested, which could affect the validity of the findings. Finally, the generalisation of the study findings is difficult since all but one study were conducted in sub-Saharan African countries with high incidence of HIV.

\section{Implications}

This study has important implications for future HIV prevention research. As a potential risk factor, the contribution of HPV infection to the HIV epidemic must be explored comprehensively, using longitudinal study designs, standardised HPV sampling and HPV genotypes classification, and analytic methods with adjustment on relevant covariates. Further research is needed to understand the aetiology of the association, including the biological mechanisms that may underlie oncogenic risk group-specific or genotype-specific associations. The effect of HPV vaccination on HIV acquisition may be assessed since there exists two highly effective HPV vaccines which have been approved for use among women, ${ }^{34}$ and one among men. ${ }^{35}$ To this day, randomised controlled trials of STI management have yielded contradictory results, which may have been partly due to the insufficient potency of the intervention, such as in the case of HSV-2. ${ }^{7}$ As indicated in the present study, there may be discrepancies regarding the HPV genotypes for which the vaccines are providing protection against, and those associated with HIV seroconversion. Hence, the development and use of vaccines covering a wider range of genotypes is necessary. Modelling studies on the potential impact of HPV vaccination campaigns on the HIV epidemic are also needed. Such research could be an important contribution to the global fight against HIV.

\section{CONCLUSION}

The observed association of HPV infection with HIV acquisition has important public health implications. If the causal association between HPV and HIV acquisition is verified, HPV vaccination, along with other biomedical interventions, has the potential to be an additional HIV control strategy, with the unique advantage of providing long-term benefits to both men and women.

\section{Key messages}

- The association between HIV acquisition and genital human papillomavirus (HPV), a major burden of morbidity and mortality worldwide, has received limited attention.

- It is, however, biologically plausible that HPV enables HIV infection and further research is required to elucidate the biological mechanisms involved.

- This review and meta-analysis suggests that HPV-infected individuals have twice the risk of acquiring HIV.

- HPV infection may be a risk factor of HIV acquisition. The effect of HPV vaccination on HIV infection should be assessed.

\section{Handling editor Jackie Cassell}

Contributors PL and BA conducted the systematic review and the meta-analyses. All authors contributed, read and approved the final manuscript. PL and BA had full access to all the data in the study and had final responsibility for the decision to submit for publication.

Funding This work was supported by the Agence Nationale de Recherche sur le Sida et les hépatites virales (ANRS-12126) France; Institut National de la Santé et de la Recherche Médicale (INSERM), France; Université de Versailles-Saint-Quentin France; the Bill and Melinda Gates Foundation (grant number OPP1021324). The funding agencies had no role in study design, the collection, analysis, and interpretation of data, in the writing of the report, and in the decision to submit the paper for publication.

\section{Competing interests None.}

Provenance and peer review Not commissioned; externally peer reviewed.

Open Access This is an Open Access article distributed in accordance with the Creative Commons Attribution Non Commercial (CC BY-NC 3.0) license, which permits others to distribute, remix, adapt, build upon this work non-commercially, and license their derivative works on different terms, provided the original work is properly cited and the use is non-commercial. See: http://creativecommons.org/ licenses/by-nc/3.0/

\section{REFERENCES}

1 Fleming DT, Wasserheit JN. From epidemiological synergy to public health policy and practice: the contribution of other sexually transmitted diseases to sexual transmission of HIV infection. Sex Transm Infect 1999;75:3-17. 
2 Chen L, Jha P, Stirling B, et al. Sexual risk factors for HIV infection in early and advanced HIV epidemics in sub-saharan Africa: systematic overview of 68 epidemiological studies. PLOS ONE 2007;2:e1001.

3 Boily MC, Baggaley RF, Wang L, et al. Heterosexual risk of HIV-1 infection per sexual act: systematic review and meta-analysis of observational studies. Lancet Infect Dis 2009;9:118-29.

4 Ward $\mathrm{H}$, Ronn M. Contribution of sexually transmitted infections to the sexual transmission of HIV. Curr Opin HIV AIDS 2010;5:305-10.

5 White RG, Orroth KK, Glynn JR, et al. Treating curable sexually transmitted infections to prevent HIV in Africa: still an effective control strategy? J Acquir Immune Defic Syndr 2008;47:346-53.

6 Sexton J, Garnett G, Rottingen JA. Metaanalysis and metaregression in interpreting study variability in the impact of sexually transmitted diseases on susceptibility to HIV infection. Sex Transm Dis 2005:32:351-7.

7 Hayes R, Watson-Jones D, Celum C, et al. Treatment of sexually transmitted infections for HIV prevention: end of the road or new beginning? Aids 2010;24 (Suppl 4):S15-26.

8 de Jong MA, Geijtenbeek TB. Human immunodeficiency virus-1 acquisition in genital mucosa: Langerhans cells as key-players. J Intern Med 2009;265:18-28.

9 Fox J, Fidler S. Sexual transmission of HIV-1. Antiviral Res 2010;85:276-85.

10 Baseman JG, Koutsky LA. The epidemiology of human papillomavirus infections. Journal of Clinical Virology 2005;32(Suppl 1):S16-24.

11 Tota JE, Chevarie-Davis M, Richardson LA, et al. Epidemiology and burden of HPV infection and related diseases: implications for prevention strategies. Preventive Medicine 2011:53(Suppl 1):S12-21.

12 Veldhuijzen NJ, Snijders PJ, Reiss P, et al. Factors affecting transmission of mucosal human papillomavirus. Lancet Infect Dis 2010;10:862-74.

13 WHO-ICO. Human papillomavirus and related cancers: summary report update. Barcelona: Information Centre on HPV and Cervical Cancer, 2010.

14 Woodhall S, Ramsey T, Cai C, et al. Estimation of the impact of genital warts on health-related quality of life. Sex Transm Infect 2008;84:161-6.

15 Pirotta M, Ung L, Stein A, et al. The psychosocial burden of human papillomavirus related disease and screening interventions. Sex Transm Infect 2009;85:508-13.

16 Bruni L, Diaz M, Castellsagué $X$, et al. Cervical human papillomavirus prevalence in 5 continents: meta-analysis of 1 million women with normal cytological findings. J Infect Dis 2010;202:1789-99.

17 Smith JS, Gilbert PA, Melendy A, et al. Age-specific prevalence of human papillomavirus infection in males: a global review. J Adolesc Health 2011:48:540-52.

18 Ng'ayo MO, Bukusi E, Rowhani-Rahbar A, et al. Epidemiology of human papillomavirus infection among fishermen along Lake Victoria Shore in the Kisumu District, Kenya. Sex Transm Infect 2008;84:62-6.

$19 \mathrm{Ng}$ 'andwe C, Lowe JJ, Richards PJ, et al. The distribution of sexually-transmitted Human Papillomaviruses in HIV positive and negative patients in Zambia, Africa. BMC Infect Dis 2007:7:77.

20 Didelot-Rousseau MN, Nagot N, Costes-Martineau V, et al. Human papillomavirus genotype distribution and cervical squamous intraepithelial lesions among high-risk women with and without HIV-1 infection in Burkina Faso. Br J Cancer 2006;95:355-62

21 Safaeian M, Kiddugavu M, Gravitt PE, et al. Determinants of incidence and clearance of high-risk human papillomavirus infections in rural Rakai, Uganda. Cancer Epidemiol Biomarkers Prev 2008:17:1300-7.

22 Marais DJ, Passmore JA, Denny L, et al. Cervical and oral human papillomavirus types in HIV-1 positive and negative women with cervical disease in South Africa. J Med Virol 2008;80:953-9.

23 Yamada R, Sasagawa T, Kirumbi LW, et al. Human papillomavirus infection and cervical abnormalities in Nairobi, Kenya, an area with a high prevalence of human immunodeficiency virus infection. J Med Virol 2008;80:847-55.

24 Banura C, Franceschi S, van Doorn LJ, et al. Prevalence, incidence and clearance of human papillomavirus infection among young primiparous pregnant women in Kampala, Uganda. Int J Cancer 2008:123:2180-7.

25 Rowhani-Rahbar A, Hawes SE, Sow PS, et al. The impact of HIV status and type on the clearance of human papillomavirus infection among Senegalese women. J Infect Dis 2007; 196:887-94.
26 Kahesa C, Mwaiselage J, Wabinga HR, et al. Association between invasive cancer of the cervix and HIV-1 infection in Tanzania: the need for dual screening. BMC Public Health 2008:8:262.

27 Clarke B, Chetty R. Postmodern cancer: the role of human immunodeficiency virus in uterine cervical cancer. Mol Pathol 2002;55:19-24.

28 Herfs $M$, Hubert $P$, Moutschen $M$, et al. Mucosal junctions: open doors to HPV and HIV infections? Trends Microbiol 2011;19(3):114-20.

29 Nicol AF, Fernandes AT, Grinsztejn B, et al. Distribution of immune cell subsets and cytokine-producing cells in the uterine cervix of human papillomavirus (HPV)-infected women: influence of HIV-1 coinfection. Diagn Mol Pathol 2005;14:39-47.

30 Leong CM, Doorbar J, Nindl I, et al. Deregulation of E-cadherin by human papillomavirus is not confined to high-risk, cancer-causing types. $\mathrm{Br} J$ Dermatol 2010;163:1253-63.

31 Leong CM, Doorbar J, Nindl I, et al. Loss of epidermal Langerhans cells occurs in human papillomavirus alpha, gamma, and mu but not beta genus infections. J Invest Dermatol 2010;130:472-80.

32 van der Loeff MF, Nyitray AG, Giuliano AR. HPV vaccination to prevent HIV infection: time for randomized controlled trials. Sex Transm Dis 2011;38:640-3.

33 Spitzer M, Brennessel D, Seltzer VL, et al. Is human papillomavirus-related disease an independent risk factor for human immunodeficiency virus infection? Gynecol Oncol 1993:49(2):243-6.

34 Harper DM. Currently approved prophylactic HPV vaccines. Expert Rev Vaccines 2009;8:1663-79.

35 Centers for Disease Control. Recommendations on the use of quadrivalent human papillomavirus vaccine in males-Advisory Committee on Immunization Practices (ACIP), 2011. MMWR Morb Mortal Wkly Rep 2011;60:1705-08.

36 Moher D, Liberati A, Tetzlaff J, et al. Preferred reporting items for systematic reviews and meta-analyses: the PRISMA statement. PLoS Med 2009;6(7):e1000097.

37 von Elm E, Altman DG, Egger M, et al. STROBE Initiative. The Strengthening the Reporting of Observational Studies in Epidemiology (STROBE) Statement: Guidelines for reporting observational studies. Ann Intern Med 2007;147:573-7.

38 Smith-McCune KK, Shiboski S, Chirenje MZ, et al. Type-specific cervico-vaginal human papillomavirus infection increases risk of HIV acquisition independent of other sexually transmitted infections. PLoS One 2010;5(4):e10094.

39 Higgins JP, Thompson SG, Deeks JJ, et al. Measuring inconsistency in meta-analyses. Bmi 2003:327:557-60.

40 Begg CB, Mazumdar M. Operating characteristics of a rank correlation test for publication bias. Biometrics 1994;50:1088-101.

41 Egger M, Davey Smith G, Schneider M, et al. Bias in meta-analysis detected by a simple, graphical test. BMJ 1997;315:629-34.

42 Chin-Hong PV, Husnik M, Cranston RD, et al. Anal human papillomavirus infection is associated with HIV acquisition in men who have sex with men. Aids 2009:23:1135-42.

43 Veldhuijzen NJ, Vyankandondera J, van de, et al. HIV acquisition is associated with prior high-risk human papillomavirus infection among high-risk women in Rwanda. Aids 2010;24:2289-92.

44 Averbach SH, Gravitt PE, Nowak RG, et al. The association between cervical human papillomavirus infection and HIV acquisition among women in Zimbabwe. Aids 2010;24:1035-42.

45 Smith JS, Moses S, Hudgens MG, et al. Increased risk of HIV acquisition among Kenyan men with human papillomavirus infection. J Infect Dis 2010;201:1677-85.

46 Auvert B, Marais D, Zarca K, et al. High risk HPV infection is associated with HIV acquisition among South African female sex workers. Infect Dis Obstet Gynecol 2011:2011:692012.

47 da Silva GK, Guimaraes R, Mattevi VS, et al. The role of mannose-binding lectin gene polymorphisms in susceptibility to HIV-1 infection in Southern Brazilian patients. Aids 2011;25:411-18.

48 Van de Perre $P$, Segondy $M$, Foulongne $V$, et al. Herpes simplex virus and HIV-1: deciphering viral synergy. Lancet Infect Dis 2008;8:490-7.

49 Giuliano AR, Nielson CM, Flores R, et al. The optimal anatomic sites for sampling heterosexual men for human papillomavirus (HPV) detection: the HPV detection in men study. J Infect Dis 2007;196:1146-52.

50 Steben M, Duarte-Franco E. Human papillomavirus infection: epidemiology and pathophysiology. Gynecol Oncol 2007;107(2 Suppl 1):S2-5. 